\title{
Innovations in design and production of spiroid gears in the XXI century
}

\author{
Veniamin Goldfarb, Evgenii Trubachev", and Natalya Barmina \\ ${ }^{1}$ Institute of Mechanics, Kalashnikov ISTU, 426069, Izhevsk, Russian Federation
}

\begin{abstract}
The paper presents the review of directions of development of the theory and practice of spiroid gears for the past two decades within the scientific production complex of Kalashnikov ISTU that involves the scientific department "Institute of Mechanics" and the small innovative enterprise "Mechanic". This enterprise became de facto the tasksetter and main investor of scientific and practical developments that can be divided into mutually related developments of the theory of gearing and methods of gear design, development of new varieties and advancement of the known gears, development of competitive layouts of gearboxes and development of efficient techniques of gear and gearbox production. Development of the theory of gearing focused on creation of computer-aided means of design (the main of them is the software system "SPDIAL+") provides the profound investigation of the process of tooth interaction with account of errors, elastic and elastoplastic strains of teeth and other elements of the design, localization of multi-pair contact, application of new schemes of tooth generation, optimization gear design with due regard to gear adaptation to real operation conditions and limitations of design and manufacturing procedures. Development and advancement of different types of gears, their design and manufacturing techniques were mainly motivated by their implementation in the specific and under-investigated application area - low-speed heavy-loaded drives for pipeline valves. The practical effect of the development is illustrated by examples.
\end{abstract}

\section{Introduction}

In 2019 the scientific department "Institute of Mechanics" of Kalashnikov Izhevsk State Technical University celebrates its $25^{\text {th }}$ anniversary. On the one hand, its foundation became the statement of the fact that a team of active scientists and engineers was formed in the University, capable of solving various problems of investigation, design and production of gears and gearboxes. On the other hand, it was the consequence of the challenge of abrupt reduction of financing the applied sciences and innovations produced in universities that was stimulated by two sources: the university budget and contracts between the university and industrial enterprises. After a short period of time a small innovative production enterprise "Mechanic" appeared. Along with the "Production engineering" department these structures formed the scientific educational production complex where the corresponding goals and functions were closely intertwined, therefore enriching each other.

The scientific and production premises in the field of gears and gearboxes accumulated in the Soviet period, got a new development mainly aimed at the requirements to become the best ones and more efficient at the market of drive engineering. Innovations became not only an interesting issue, but the required condition for survival. In this paper we tried to state in short the essence and effect of innovations in the field of design and production of spiroid gears, assuming to extend this experience further.

\section{Spiroid gear as the main object of in- vestigation and developments}

The history of invention of spiroid gear varieties and methods of their production is described in details in works by Prof. V. I. Goldfarb [1] and V. Bolosh [2]. As it is related to worm gears according to design and production procedures, a spiroid gear is similar to the hypoid one by layout features (Fig. 1) [1]. Since the time of its invention till present, in many respects, spiroid gearing has been the innovation by itself. Its innovative character (implementation replacing the traditional solutions) is stipulated by aspiration to use its advantages over analogs:

- higher load and overload carrying capacity, static strength provided by multi-pair contact and other favorable properties of meshing, or (another aspect of the same matter) smaller dimensions and cost of the drive;

- better smoothness of operation;

- less sensitivity to action of errors;

- applicability of heat strengthened steel for production of a gearwheel rim instead of antifriction materials;

- possibility of simple backlash adjustment up to its complete elimination, moreover, during the gear operation - by axial displacement of the bevel worm or (in most cases by insignificant breaking the conjugation of gearing) of the gearwheel;

- possibility of application of the widely spread comparatively simply adjusted equipment for gear cutting.

\footnotetext{
Corresponding author: truba@istu.ru
} 


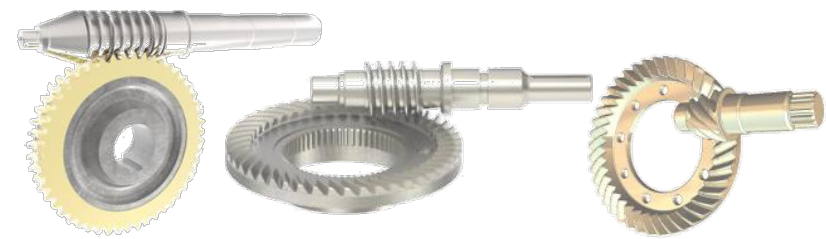

Fig. 1. Spiroid gear (in the center) and its analogs - worm (at the left) and hypoid (at the right) gears.

A great amount of varieties of spiroid gears are known, in which the pointed advantages are implemented for these or those drives and production conditions. All this makes application of spiroid gears attractive for consumers and convenient and cheap for production.

Practically since the very first years of spiroid gear appearance, an interesting engineering technique of its design has been proposed [3]. A little different version of it has been developed in the USSR [4]. In both techniques the correlations between gear parameters are introduced that provide rather workable solutions. However, it is nearly always insufficient in practical design. Investigations $[5,6]$ showed, that the significant effect can be achieved by varying the gear parameters which is considerably different from varying the same or similar parameters in worm gears and it non-obviously influences the gear characteristics. Nearly always there are geometrical limitations of the choice - undercut and pointing of gearwheel teeth and worm threads. All this makes it necessary to apply the computer-aided design of spiroid gears in order to develop competitive products.

\section{Design objectives and methods of analysis}

The following assignments solved at design of spiroid gears, their features and implementation within the software system of investigation and design of spiroid and worm gears "SPDIAL+" (which is our main means of design) are considered in details in [7-12]:

1. Development of the conjugate gearing:

- synthesis of gear scheme [8];

- analysis of geometry of conjugate surfaces;

- analysis of geometry and kinematics of the conjugate gearing;

- analysis of forces acting in meshing, efficiency and loading characteristics of the gear;

2. Synthesis of the localized contact [9];

3. Geometrical analysis of gearing with account of errors (TCA) [10];

4. Analysis of the loaded gearing (LTCA), including the elastic [11] and elastoplastic statements [12].

The feature of the gearing analysis is the application of our proposed technique which implies that the normal line to the basic generating surface is represented as the vector field of normal lines in the fixed space [13], that is, by Cartesian coordinated of the fixed space $\mathbf{n}=\mathbf{n}(x, y$, $z$ ) rather than by curvilinear coordinates-parameters of the surface (as it is usually done). It allows for effectively preventing the tooth undercut [14], solving the objectives of analysis of the conjugate gearing and synthesis of the localized contact. Note here, that the priority in application of the concept of the vector field of normal lines in the fixed space in a little different statement (to obtain or exclude certain special properties of gearing) belongs to Prof. F. L. Litvin and Prof. M. L. Erikhov [15] and also to $\mathrm{PhD} \mathrm{S}$. A. Lagutin who generalized this issue [16].

We perform synthesis of the localized contact in accordance with three procedures (they are enumerated with increase of complication) $[9,17]$ :

- by local characteristics at the assigned design points;

- by parameters of modification fields;

- by phases of reconjugation in the multi-pair loaded contact.

The basics of solving the $3^{\text {rd }}$ and $4^{\text {th }}$ assignments are the field of clearances between contact flanks along all their areas that can come into contact. Within the analysis of the loaded gearing the spiroid gear is considered as the multiply statically indeterminate system with oneway links.

\section{Production of spiroid gearboxes}

The production activity carried out at our center is in many respects unusual for the mechanical engineering enterprise. We do not possess any super-advanced or unique equipment and tools for machining and we have never had any valuable external investment of our developments. One has to add "unfortunately" (who of the scientists and manufacturers would refuse from such a support?!). Nevertheless, maybe the state of being left to ourselves is one of the main motivations for innovations that provide our confident status at the gear market.

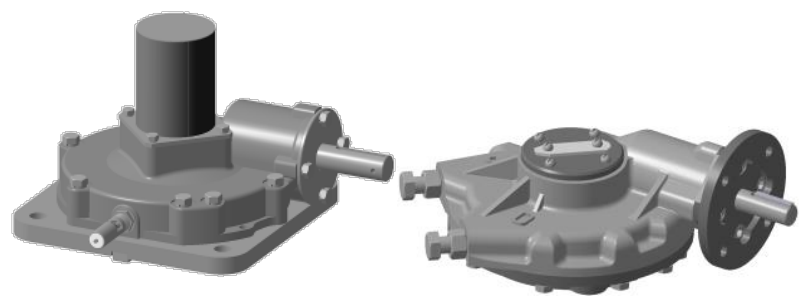

Fig. 2. Spiroid gearboxes for pipeline valves - multi-turn (for wedge valves, at the left) and quarter-turn (for ball valves and valve gates, at the right).

One of the most successful assets for application of our developments are the gearboxes for controlling the pipeline valves (Fig. 2) [18] that operate at low rotational speeds of shafts (high-speed stages - not more than 100$200 \mathrm{rev} / \mathrm{min}$ ), infrequent activations and short-term peak torques. It is accustomed to consider, that opposite conditions - high speeds, frequent activation and long-term loads - require a certain craft in design and production. But simplicity of operating conditions of pipeline valve drives is very deceptive. Aimed at shortening the costs and correspondingly, as a rule, mass and overall dimensions of pipeline valve gearboxes, the leading manufacturers achieved outstanding results as compared to gearboxes from other areas of drive equipment application: the ratio of the gearbox mass to the transmitted torque reaches 0.005 and even less in the best samples. In particular, Fig. 3 illustrates the way the exterior and dimen- 
sions of spiroid gearboxes were changing for different generations of development. The charge for decreasing the gearbox dimensions is the increase in the loaded state of practically all elements of the design (bending fractures of gearwheel teeth and worm threads, progressive crumpling and scuffing of tooth flanks, fractures of casing parts, fasteners, breakage of bearings - here is the list of basic risks to be avoided under design) and appearance of a great number of layout schemes. Here one should add manufacturing restrictions and, finally, the necessity to meet various requirements of consumers as related to gear ratios, mounting, and convenience of gearbox layout and gearbox control.

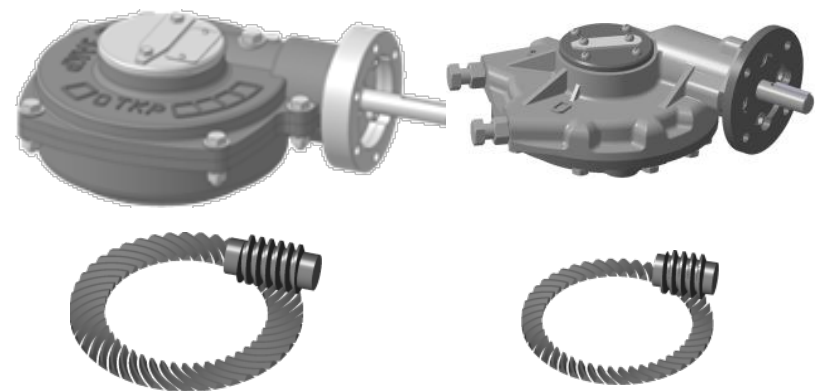

Fig. 3. Spiroid gearboxes of the $1^{\text {st }}$ (at the left) and the $3^{\text {rd }}$ (at the right) generations of development and gears applied there.

At present time our serial production comprises about 30 gears differing by types, dimensions (gearwheel diameters from 20 to $450 \mathrm{~mm}$ ), gear ratios (from 1 to 120 at one stage); monthly programs usually count about 30 40 varieties at the total number of gears up to 1000 . The tendency of increase in the range and number of gears is existing practically all the life period of the center functioning. One could imagine that, with regard to our rare assets, the efficient production is possible only if each of the gears is optimized with account of conditions of our plant, thus providing quick and cheap preparation of the latter and the consequent efficient gearbox production. Herewith, each object of production is preceded by hundreds of layout designs with a great number of assessments.

Evolution of spiroid gearboxes for pipeline valve drives can be followed by comparison (Fig. 3 and Table 1) of different generations of one item.

Without focusing on features of design [18, 19], let us pay attention to the following main advantages of gearboxes of the latest models:

- the relative gearbox mass has significantly decreased: for the dimension type shown in Fig. 3 - from 0.009 to $0.005 \mathrm{~kg} / \mathrm{Nm}$;

- the possibility to implement various versions of flange mounting of the gearbox to the valve is provided;

- the wider range of gear ratios is ensured.

It is evident, that the mentioned progress is to a great extent the result of the design engineering activity. Experience of refining the design decisions for spiroid gears gives ground for certain important, to our opinion, tendencies of design engineering.
Table 1. Comparison of characteristics of gearboxes of the $1^{\text {st }}$ and $3^{\text {rd }}$ generations and their spiroid gears.

\begin{tabular}{|c|l|c|c|}
\hline $\mathrm{N}$ & Parameter/characteristics & $\begin{array}{c}\text { Generation 1 } \\
\text { RZA-S-1600 }\end{array}$ & $\begin{array}{c}\text { Generation 3 } \\
\text { RZA-S-2000 }\end{array}$ \\
\hline 1. & $\begin{array}{l}\text { Center distance (offset), } \\
\text { mm }\end{array}$ & 60 & 60 \\
\hline 2. & $\begin{array}{l}\text { Diameter of the gearwheel, } \\
\mathrm{mm}\end{array}$ & 200 & 175 \\
\hline 3. & Mass, kg & 22.5 & 18.5 \\
\hline 4. & $\begin{array}{l}\text { Efficiency at operation of } \\
\text { right/left tooth flanks }\end{array}$ & $0.41 / 0.35$ & $0.43 / 0.38$ \\
\hline 5. & Gear ratio & $24 ; 46$ & $11-92$ \\
\hline 6. & $\begin{array}{l}\text { Loading torque at control } \\
\text { from the electric drive, Nm }\end{array}$ & 1560 & 2000 \\
\hline 7. & $\begin{array}{l}\text { Loading torque at manual } \\
\text { control, Nm }\end{array}$ & 2450 & 3500 \\
\hline 8. & $\begin{array}{l}\text { Contact stresses at meshing } \\
\text { of right/left tooth flanks, } \\
\text { MPa }\end{array}$ & $1300 / 800$ & $1950 / 930$ \\
\hline
\end{tabular}

\section{Features of gear design}

\section{The best gear is not the best solution for the gearbox}

The main reason for this is the presence of a great number of geometrical restrictions: intersection of structural elements of the gearbox and parts of the machine-tool settings. One portion of these restrictions is imposed by the driven equipment (in our case - pipeline valve): its attachment flange and the driven shaft. These elements are central with the structural elements of the gearbox (and therefore, the gear) arranged around. The second portion of restrictions is related to the risk of mutual intersection of structural elements with each other. These structural elements are the gear elements, gearwheel hub, bearings and parts supporting them. Fig. 4 shows the fragments of geometrical simulation of possible intersections [18].
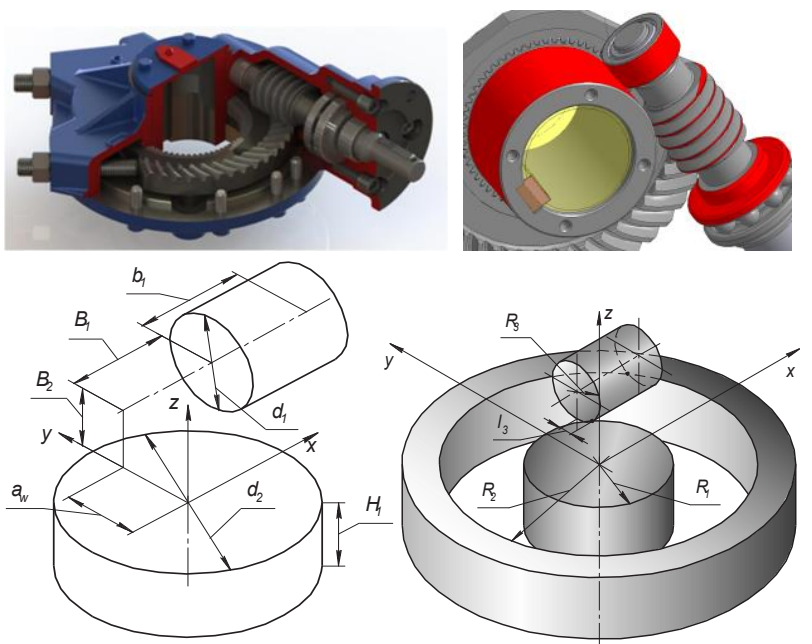

Fig. 4. Fragments of simulation of restrictions - intersection of parts.

Because of the restrictions, the gear often forcedly has a little greater dimensions than it is necessary for transmission of the assigned torque, thus, the means of improving the gear turn to be limited too. Generally speaking, minimization of gear dimensions worsens a lit- 
tle the design solution. Moreover, certain gear parameters can be corrected up to worsening the gear itself, but it will lead to improving the gearbox as a whole. For instance, last generation gearboxes comprise gearwheels with narrower gear rims (Fig. 3), thus decreasing the dimensions of the gearbox.

\section{The best gear is not the best solution for production}

"Costs of gear-cutting tools make up at least $50 \%$ of the producing cost of gear machining", states the desk reference book [20, p. 105] of the Soviet gear manufacturer. One can argue the correctness of this statement, but no doubt, the part of these costs is very essential. One of effective and widely tested ways of cost reduction is unification of gear cutting tools that allows for shortening their range and cost of production and operation.

Several dozens of the best (ultimately improved) worm-type gears that are simultaneously in production are not a bounty gift for the manufacturer. Each of these gears requires an individual hob. Moreover, these hobs include multi-thread ones, the main problem of such a production becomes therefore obvious. We developed and implemented the alternative approach to unification of spiroid hobs and worm ones - the method of localized contact analysis and the new method of gear design $[7$, 21] where each of the available tools (mainly, singlethread) is applied for cutting gearwheels paired with worms having different thread numbers and diameters. This difference in approaches is visually shown in Fig. 5.

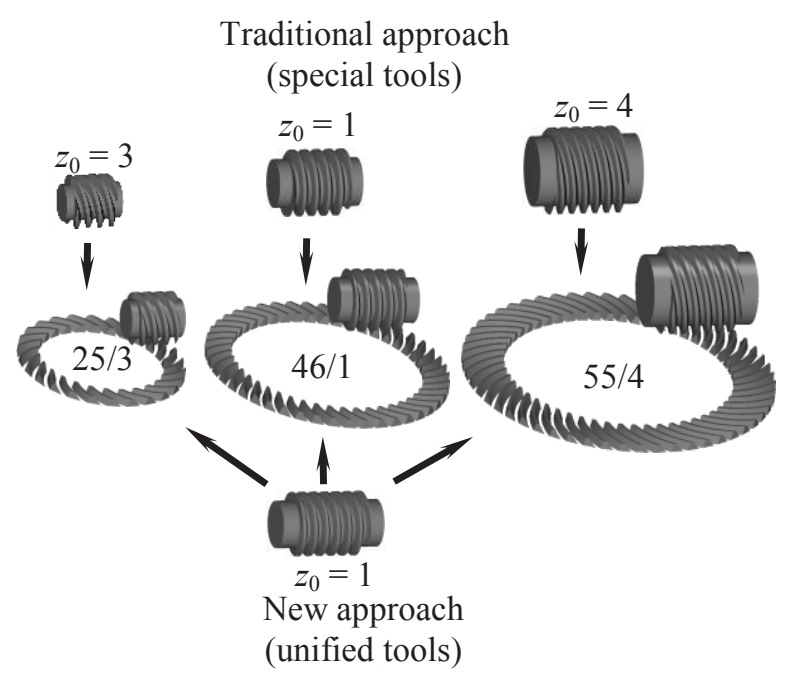

Fig. 5. Traditional and implemented new approaches to design and production of spiroid gears.

Due to the new approach the design process is subject to the choice of the tool. It imposes limitations upon the choice of parameters, thus making the gear not the best one, but favorable for the production.

The best gearbox comprises gears, each of them individually being not the best solution

Even if we take into account the restrictions, the best individually taken gear does not mean the best solution for the gearbox in which several gear ratios are implemented. Maximal improvements of each of the applied gears requires, strictly saying, the individual combination of parameters. Designing in these conditions is either a compromise in meeting the requirements of improving each of the gears, or it is subject to improvement of the most important of them, the rest remains in some way non-optimal.

Certainly, by using the words "the best gear" we meant their most common concern - the gear possessing the best operational characteristics. Indeed («Captain Obvious») this meaning should be added by ".... and convenient for production, cheap in production and production-efficient". The integrated account of all these features can be expressed in an optimization algorithm [22], where the structural and production requirements are stated as restrictions-equalities and restrictionsinequalities. Terms of correspondence to requirements of gear operation characteristics and the degree of contact localization depending on the main design objective are stated either as restrictions-inequalities, or as the target function to be minimized or maximized.

\section{Gear machining}

The main motivation for innovations is traditional here to provide minimum production costs. The components of minimization are: principle of versatility (when a whole range of gears is being produced); increase in production efficiency; cheapening the production preparation which, in turn, is determined by simplification of tools and equipment, their setting and resetting. Our recent innovations have been aimed exactly at this. Let us consider them.

\section{Unification of spiroid hobs}

This innovation has already been mentioned above. Once again let us emphasize three main effects of its implementation:

- simplification of tools: single- and double-threaded hobs are applied instead of multiple-thread ones;

- abrupt (practically by one order) decrease in the range of tools;

- contact localization is provided in gears.

At least two versions of its implementation are possible within a specific enterprise $[7,21]$ :

A) to determine the maximum number of various gears for which available tools are applicable;

B) to determine the minimum number and parameters of tools for production of the pointed gears.

Historically there has been a combination of these two versions at out center: a part of tools has already been available from the beginning of the approach implementation; and new tools have been designed and produced based on the necessity to produce new gears. As a result, interrelated sets of hobs ( 8 dimensions) and serially produced gears (about 70 essentially different by dimensions and gear ratio) have been formed - Fig. 6. Each arrow in Fig. 6 corresponds to two or three gears different by the number of worm threads. 
Axial module $m_{x 0}$ of the hob, $\mathrm{mm}$

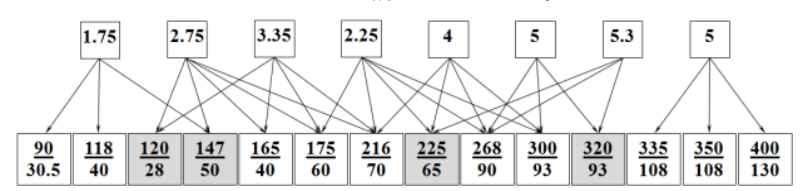

Outer diameter of the gearwheel, $\mathrm{mm}$

Fig. 6. Ranges of spiroid hobs and produced gears (grey colored cells are for multi-turn gearboxes, the rest are for quarterturn gearboxes).

\section{Highly efficient method of worm thread machining}

Our implemented method of thread machining by means of the face cutting head [22] can not be considered new, strictly saying. Worms of the corresponding types were even standardized in the USSR; they are worms ZK3, ZCT3 (State Standard GOST 18498-89) and SZK3, SZCT3 (State Standard GOST 22850-77). The generating tool for them is the cup-type tapered or toroidal one. Due to the increased rigidity and the presence of a great number of cutters, the high production efficiency of thread machining is provided. The new aspects of the method are, to our opinion, as follows:

- implementation at a commonly applied equipment CNC lathe (Fig. 7);

- mew methods of setting and resetting, providing fine adjustment and profile modification [22];

- assembled structure of the cutter holder with application of disposable carbide inserts.
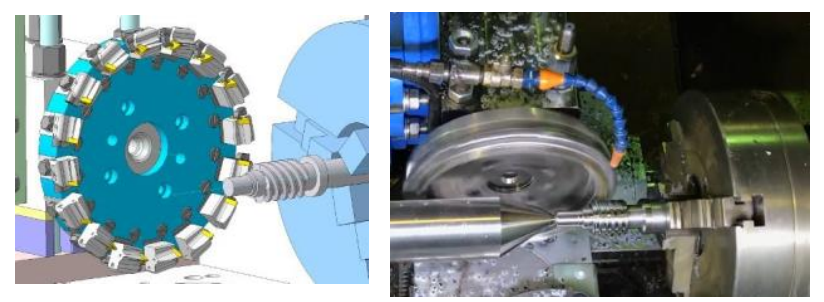

Fig. 7. Worm thread machining by the cutter head at CNC lathe.

Application of this technique provides a multiple effect at machining - up to 5-6 times as compared to cutting by a traditional high-speed steel profile cutter; and it promotes application of this technique as an alternative to grinding of heat-strengthened worms.

High efficiency method of spiroid gearwheel tooth machining

Blade machining of spiroid gearwheel teeth is traditionally the technique that is hard to improve with regard to its production efficiency. The main reason is the necessity to apply a spiroid hob - it is the tool with low rigidity and bad conditions for heat transfer and chip removal; and it is problematic to make it assembled with application of hard-alloy plates. The new scheme (Fig. 8a) which we have proposed in $[23,25]$ and are implementing in serial production implies application of the assembled tool with hard-alloy plates - a face cutter head (Fig. 8 b) - and it can be implemented at the CNC milling ma- chine or lathe after their little upgrade of the mechanical part and the control system.

The main advantages provided by implementation of the new scheme are:

- increase in the production efficiency;

- versatility of the tool - possibility of its application for gearwheels of gears having various dimensions, numbers of threads and worm modules;

- absence of necessity to regrind the tool;

- possibility of simple control by profile and longitudinal modification of tooth flanks;

- application of common machine-tools;

- simple and obvious techniques of machine-tool setting.

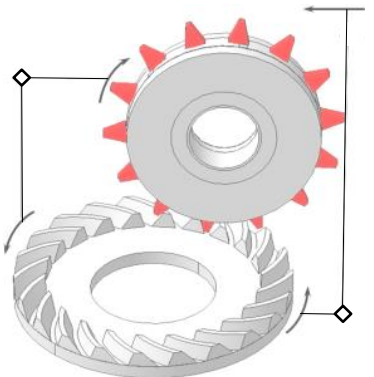

a)

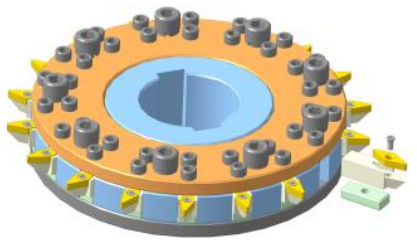

b)
Fig. 8. New scheme of spiroid gearwheel tooth machining (a) and the tool for this purpose (b).

\section{Innovations for a special case - spiroid gears with small gear ratios}

Spiroid gears with small gear ratios $(i \leq 8)$ appeared in the practice of pipeline valve gearbox production as an effective alternative to bevel ones that have been actually dominating in multi-turn gearbox engineering. One can emphasize three components of the efficiency of the new solution: technical (spiroid gearboxes have an essentially smaller mass), organization (it became significantly easier to produce gears with different gear ratios) and install them into one gearbox casing and, finally, economic (provided by the price gain). Also, application of spiroid gears with small gear ratios instead of hypoid ones is the wrongly abandoned (since the first serious attempts in 1970 s $[26,27])$. This theme is mainly related to gearboxes of drive shafts of transport equipment: trucks and cars, trams, locomotives and so on. The main motivation to develop such an alternative is the high cost of the existing and, one can say, capturing all the world technique that implies application of expensive and specialized equipment and training of special staff at all stages of production preparation and implementation. Exactly these difficulties are often the stumbling stone for many traditional and potential manufacturers. In justice, the traditional technique is rather highly developed in many respects: regarding both production efficiency and the quality of design and production solutions.

The main problem for spiroid gears with small gear ratios is the increased (as compared to common spiroid gears) number of worm threads: for $i \leq 8$ it is usually $\mathrm{z}_{1}$ $\geq 4$, and for $i \leq 5$ it is $z_{1} \geq 6$. It makes problems in gear machining for both gear elements. When machining the worm threads, the number of tool idle runs is increased, thus increasing the machining time and introducing the additional error. Machining of gearwheel teeth leads to 
even greater difficulties: it requires application of multithread hobs that are expensive in production and operation.

In the new method of multiple worm thread machining [23] the same engineering support is applied as for the described above technique of thread machining by a face cutter head. The essential difference is that a kinematic link is produced between rotations of the tool and the workpiece (Fig. 9), the gear ratio is equal here to the ratio of the number of the cut threads to the number of cutters (to be exact, pairs of cutters, each of them machining one of the thread flanks) of the cutter head. Therefore, threads are machined per one working pass of the tool at a continuous indexing of threads. Other schemes of the continuous indexing are also possible [23] at common $\mathrm{CNC}$ lathes with their relatively cheap upgrading.

The problem of multi-thread tools and effective control of the level of contact localization can be solved by two innovations described above:

- calculation of the machine-tool setting for a hob with a small number of threads (for a four-thread worm it is possible to apply a double-thread hob, and for the 6-7thread worm a three-thread hob is applicable);

- application of the face cutter head.

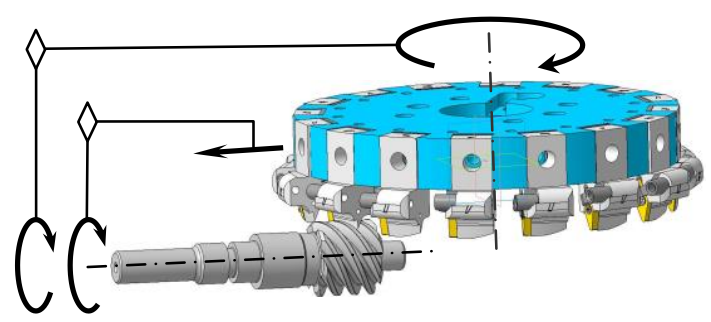

Fig. 9. New scheme of machining the multiple worm threads.

Another alternative in machining of spiroid gearwheel teeth is related to application of a multi-tooth running-in cutter (Fig. 10). This scheme is the known one [27]. As for the new solution based on our method of synthesis of the localized contact it is proposed to increase the number of threads of the generating worm rather than decrease it. The main effects of this proposal are as follows:

- The tool diameter is increased, thus

- providing the increase in its rigidity;

- providing the layout possibility of the assembled structure;

- The additional possibility to control the level of the longitudinal contact localization.
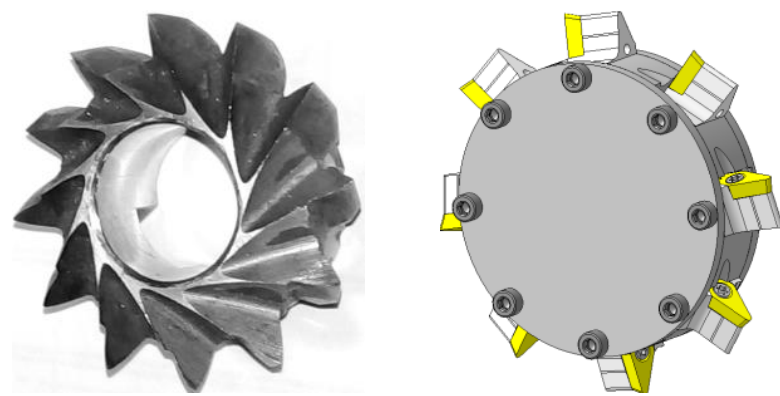

Fig. 10. Running-in cutters: the traditional solid structure (a) and assembled structure (b).
The running-in cutter turns in reality into a cutter head (Fig. 10b) equipped with the hard-alloy plates that can be competitive to traditional cutter heads. To our opinion, it is reasonable to implement high rotational speeds of elements at gear machining according to this scheme at the CNC milling machine or lathe after their little upgrading.

In most cases it is likely possible to produce the alternative spiroid gear with practically the same sizes of gear elements and mounting dimensions as the hypoid one. The design parameter that illustrates this possibility for the hypoid gear of the rear axle of "Kamaz" truck is shown in Table 2.

In both cases of the alternative spiroid gear there are efficient possibilities of controlling the level and location of contact localization - variation of curvature of worm profiles, ratios of their modules, numbers of threads, machine-tool interaxial angle and choice of arrangement of design points. Fig. 11 shows the obtained modification fields of teeth.

Table 2. Example of substitution of the hypoid gear of "Kamaz" truck by the alternative spiroid one.

\begin{tabular}{|c|c|c|c|c|}
\hline \multirow{2}{*}{\multicolumn{2}{|c|}{ Parameter }} & \multirow{2}{*}{$\begin{array}{l}\text { Hypoid } \\
\text { gear }\end{array}$} & \multicolumn{2}{|c|}{ Spiroid gear ${ }^{*}$} \\
\hline & & & version 1 & version 2 \\
\hline \multicolumn{2}{|c|}{$\begin{array}{l}\text { Center distance (offset), } \\
\mathrm{mm}\end{array}$} & \multicolumn{3}{|c|}{30} \\
\hline \multicolumn{2}{|c|}{$\begin{array}{l}\text { Outside diameter of the } \\
\text { gearwheel, } \mathrm{mm}\end{array}$} & \multicolumn{3}{|c|}{379.5} \\
\hline \multicolumn{2}{|c|}{$\begin{array}{l}\text { Diameter of pinion tips, } \\
\mathrm{mm}\end{array}$} & $97.7^{* *}$ & 95 & 95 \\
\hline \multicolumn{2}{|c|}{ Face angle, ${ }^{\circ}$} & 17.3 & 0 & 0 \\
\hline \multicolumn{2}{|c|}{ Gear ratio } & $43: 9$ & $29: 6$ & $38: 8$ \\
\hline \multicolumn{2}{|c|}{ Module $^{* * *}, \mathrm{~mm}$} & 8.8 & 5.8 & 5.52 \\
\hline \multicolumn{2}{|c|}{ Pinion spiral angle, ${ }^{\circ}$} & 45 & 22.5 & 27.3 \\
\hline \multirow{2}{*}{ 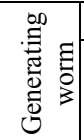 } & Number of threads & - & 3 & 10 \\
\hline & Diameter, mm & - & 67.5 & 128.0 \\
\hline
\end{tabular}

*version 1 corresponds to cutting the gearwheel by a hob; version 2 - by a running-in cutter;

${ }^{* *}$ at the middle face section;

*** for a hypoid gear - external circumferential, for a spiroid gear - axial.

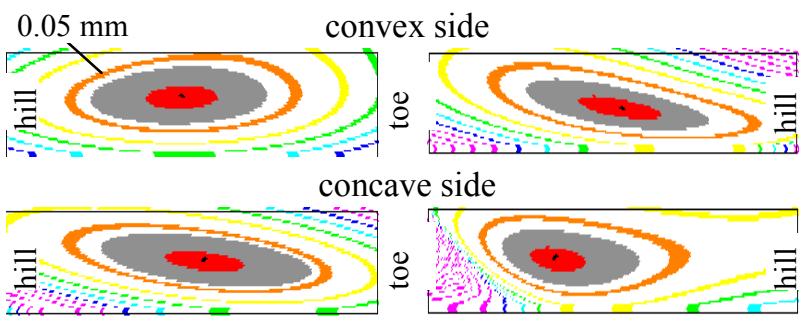

Fig. 11. Modification fields of teeth on elevation views of teeth for alternative versions $(1-$ at the left, 2 - at the right) of a spiroid gear.

Implementation of spiroid gears as an alternative to hypoid ones provides the following gains:

- application of simpler and cheaper equipment;

- greater flexibility of the technique, simpler re-setting of the equipment, thus providing an easier transfer from one parameters to others, from production of a series of 
one type of gears to production of a series of other gears; - meshing becomes insensitive to the error of axial arrangement of the pinion (spiroid worm), thus simplifying the assembly.

\section{Conclusion}

A spiroid gear "in the right hands" is a convenient object of design and production that provides many progressive improvements as compared to traditional solutions. To our opinion, the enumerated in the paper innovations make this object even more competitive. Many of these innovations have prospects of wide implementation or have already been implemented for other types of gears, thus making their production more convenient and costsaving.

\section{References}

1. V. I. Goldfarb, Proc. of the Int. Conf. on Mechanical Transmissions. China, 1, Science Press, 19-26 (2006)

2. V. Boloş, Scientific Bulletin of the „Petru Maior” Univ. of Tîrgu Mureş 7 (XXIV), 2 (2010)

3. W. D. Nelson, Machine Design, vol. 33, 4 (136144), 5 (93-100), 6 (165-171) (1961)

4. A. K. Georgiev, V. I. Goldfarb, S. V. Ezerskaya, Standard OST-3-4290-79 (in Russian)

5. V. I. Goldfarb, S. V. Ezerskaya, Izvestiya Vuzov J, Mashinostroeniye, 2, 184-186 (1975) (in Russian)

6. V. I. Goldfarb, A. S. Kuniver, E. S. Trubachev, A. V. Monakov, Proc. of $4^{\text {th }}$ World Congress on Gearing and Power Transmissions, 1, France, 365-375 (1999)

7. V. I. Goldfarb, E. S. Trubachev, S. V. Lunin, Proc. of the ASME 2007 Int. Design Engineering Technical Conf. \& Computers and Information in Engineering Conf., USA (2007)

8. V. I. Goldfarb, A. G. Russkikh, Proc. of the $6^{\text {th }}$ Int. Conf. on the Theory of Machines and Mechanisms, Czechoslovakia, 65-70 (1992) (in Russian)

9. V. I. Goldfarb, E. S. Trubachev, Proc. of the $11^{\text {th }}$ World Congress in Mechanisms and Machine Science. Tianjin (China), 2, 901-905 (2004)

10. V. I. Goldfarb, E. S. Trubachev, Proc. of the Int. Conf. on Gears, Germany, 197-209 (2002)

11. V. I. Goldfarb, E. S. Trubachev, A. S. Kuznetsov, Proc. of the $2^{\text {nd }}$ Int. Conf. "Power transmissions
2006", Serbia, 369-376 (2006)

12. E. S. Trubachev, A. S. Kuznetsov, A. M. Sannikov, Advanced Gear Engineering, MMS 51, Springer, 45-72, (2018)

13. E. S. Trubachev, Proc. of Int. Symp. "Theory of real gearing”, Kurgan, 80-84 (1997) (in Russian)

14. E. S. Trubachev, Vestnik Mashinostroeniya J., 7-11 (2004) (in Russian)

15. F. L. Litvin, M. L. Erikhov, Theory of gears in machines, Moscow, Mashinostroeniye, 27-38 (1970) (in Russian)

16. S. A. Lagutin, Mashinovedenie J., 4, 69-75 (1987) (in Russian)

17. E. S. Trubachev, Proc. of the Int. Symp. "Theory and practice of gearing”, Russia, 359-366 (2014) (in Russian)

18. V. I. Goldfarb et al, Spiroid gearboxes of pipeline valves, Moscow, Veche (2011) (in Russian)

19. V. I. Goldfarb, E. S. Trubachev, A. S. Kuznetsov, Armaturostroeniye J., Saint-Petersburg, 1 (94), 8087 (2015) (in Russian)

20. Production of gears (Reference book, Ed. By B. A. Taitz), Moscow, Mashinostroeniye (1990) (in Russian)

21. V. I. Goldfarb, E. S. Trubachev, Proc. of the Int. Conf. on Gears, Germany, 1755-1759 (2005)

22. E. S. Trubachev, T. V. Savelyeva, T. A. Pushkareva, Advanced Gear Engineering, MMS 51, Springer, 327-344 (2018)

23. E. Trubachev, S. Loginov, K. Bogdanov, D. Khvatov, A. Shutkina, Advanced Gear Engineering, MMS 51, Springer, 465-480 (2018)

24. E. S. Trubachev, K. V. Bogdanov, G. S. Gorbunov, Vestnik of Kalashnikov ISTU J., Izhevsk, 4 (21), 35-42 (2018) (in Russian)

25. E. S. Trubachev, P. A. Zlobina, S. E. Loginov, Intelligent systems in production J., Izhevsk, 3, 178-184 (2011) (in Russian)

26. A. K. Georgiev, Development of main spiroid gears of cars, Scientific investigation report, Izhevsk (1972) (in Russian)

27. A. K. Georgiev, Yu. I. Maltsev, I. I. Mansurov, Proc. of All-Union scientific technical meeting "Prospects of development and application of spiroid gears and gearboxes", Izhevsk, 39-45 (1979) (in Russian) 